calculated to produce a system of technical education to match the great literary and academic achievements of Scotland, which have perhaps in the past tended to obscure the activities of the technician, the artisan and the craftsman.

\section{A National Health Service}

IN "Health Abounding", issued by the Social Credit Party, 2 Fitzroy Street, London, W.1, Dr. A. T. Westlake describes the aims of the health service which is planned by the Social Credit Party. Dr. Westlake begins with some telling remarks about our existing health services and about the Government's proposals for a national health service. Our existing health services are complex and confused, and we fail to apply the knowledge that we possess. Health is largely dependent on our ability to pay for it, in spite of numerous charities and the altruism of the medical profession. Our existing health organization has, Dr. Westlake thinks, produced a magnificent service; but it contains fatal flaws, the most glaring of which is the making of a living out of ill-health. The Government's proposals for a national health scheme and the Beveridge proposals have brought matters to a head. All seem to be agreed that the future medical service will be a complete and comprehensive one covering everybody, but the problem is how best to create it. The Medical Practitioners' Union, the Socialist Medical Association and several other bodies advocate a State Medical Service; the British Medical Association seeks a compromise between the old system and the new proposals. A State medical service under present conditions can only mean, Dr. Westlake argues, rigid control of both medical man and patient, with strict certification. The Government's White Paper is not a health scheme, but a medical and sickness service; it is not a free service, for it is to be paid for by taxation, rates and social insurance. The only basis upon which can we have a free State medical service which leaves the medical man a free agent is, Dr. Westlake thinks, the Social Credit System.

The two main objects of this health service would be the health of the community organized into the cure, annihilation and prevention of disease and the promotion and maintenance of health ; and the wellbeing and skill of all those who work in the health service. Curative work will for some time engage most of its attention, because of the gigantic proportions of the disease problem. No one is likely to object to Dr. Westlake's excellent suggestions under this heading. He would treat the mind as well as the body, deal drastically with the patent medicine racket and create real health centres which would cater primarily for the healthy and only secondarily for the diseased, for whom curative centres would be provided. Dr. Westlake here draws much on the experience of the Peckham Health Centre, which has provided valuable information. Prevention of disease depends on the abolition of poverty and on proper feeding, proper housing and elimination of industrial over-fatigue. These are the problems of social medicine, which is vitally important. Problems of immunization and health education are also discussed. In his discussion of health, Dr. Westlake again refers to the work of the Peckham Health Centre. Not everyone will agree with the development of this section of the pamphlet, or with Dr. Westlake's conception of a medical guild for the promotion of health and well-being. The General Medical Council exists for the protection, not of the medical profession, but of the public. Dr. Westlake would add to its functions the welfare and interests of the medical men also. Further sections of his pamphlet deal with administration, finance, hospitals and other details.

\section{The Case for 'Planning'}

THERE pamphlets issued by the Cheam Architectural Press (price 6d. each) in "The Planning Bogies" series are too good to be popular. Those who dislike Prof. H. J. Laski are unlikely to be pleased with the way in which in "Will Planning Restrict Freedom ?" he disposes of the bogie of bureaucracy, and the more ardent planners may be restive under his trenchant delineation of the conditions which planning machinery must serve in a democracy-his insistence on the participation of the ordinary citizen is, moreover, reflected in the other pamphlets. Mr. E. S. Watkins in "How Will Planning Affect Land Ownership ?" deals with nationalization; but the pamphlet also gives an admirably lucid explanation of the existing land ownership system in Britain and of proposals for reform as contained in the Uthwatt Report and elsewhere. The broad objectives of land control-to ensure both the best economic and the best social use of our land and resources-are well stated, and also the basic requirements of control ; they lead to concrete suggestions as to the composition and areas of planning authorities and amendments to the Town and Country Planning Act, which would transfer the responsibility for planning from the existing local government authorities to ad hoc area planning committees.

Mr. E. F. Schumacher, in examining the question "What Will Planning Mean in Terms of Money ?", discusses first the case for physical planning; he believes that, when the social costs of unplanned development are taken into account, the question becomes rather whether we can afford to do without planning. Emphasizing the growing divergence between private and social costs, he examines the case for housing in further detail, and argues that physical planning is the pre-condition for the successful pursuit of a housing programme such as the Government is preparing to inaugurate. Without it a steady effective demand cannot be maintained, the programme will be wasteful and head for an early collapse.

\section{New Electron Microscope for Canada}

THe National Research Council of Canada announces the installation of the latest type of electron microscope in its Ottawa laboratories. This instrument and one developed in the Physics Department of the University of Toronto are the first electron microscopes to be used in Canada. A third microscope will be installed shortly at McGill University in Montreal. Plans to purchase this modern research instrument were made a year ago when the Council sent two physicists to the United States to study the available types. After the new R.C.A. Universel model was selected, priority application was made to the United States War Production Board, which scheduled delivery for January 1945. The Division of Physics and Electrical Engineering has provided laboratory space for the microscope and assigned a physicist in the Radiology Section to take charge of it. It is hoped to make this new electron microscope as widely available in Canada as possible to all Government laboratories and to those industries having suitable problems. 